\title{
THE EFFECT OF OXYGEN ON FATIGUE RESISTANCE COEFFICIENT OF HIGH-GRADE MEDIUM-CARBON STEEL MANUFACTURED IN ELECTRIC PROCESS AND DESULFURIZED WITH ARGON-REFINED
}

\author{
${ }^{1}$ Tomasz LIPIŃSKI, ${ }^{1}$ Anna WACH, ${ }^{2}$ Dariusz KARPISZ \\ ${ }^{1}$ University of Warmia and Mazury in Olsztyn, Olsztyn, Poland, EU, tomaszlipinski.tl@gmail.com \\ ${ }^{2}$ Cracow University of Technology, Kraków, Poland, EU, dariusz.karpisz@pk.edu.pl
}

https://doi.org/10.37904/metal.2021.4163

\begin{abstract}
The experimental material consisted of semi-finished products of high-grade, medium-carbon constructional steel with: manganese, chromium, nickel, molybdenum and boron. The experimental material consisted of steel products obtained in industry metallurgical process in electric in a 140-ton basic arc furnace and desulfurized with argon-refined. The samples were quenched and austenitized at a temperature of $880 \mathrm{oC}$ for 30 minutes. They were then cooled in water and tempered by holding the sections at a temperature of 200 , $300,400,500$ and $600 \mathrm{oC}$ for 120 minutes and air-cooled. Fatigue tests were performed with the use of a rotary bending machine at a frequency of $6000 \mathrm{cpm}$. The results were statistical processed and presented in graphic form. This paper discusses the results of oxygen content in steel on the fatigue strength characteristics of the average number of sample-damaging cycles and the average values of the fatigue resistance coefficient for various heat processing options.
\end{abstract}

Keywords: Steel, non-metallic inclusions, fatigue strength, oxide impurities, bending fatigue

\section{INTRODUCTION}

The impurity content is also a key determinant of the quality of high-grade steel. Inclusions may also play an important role, subject to their type and shape. Inclusions may increase the strength of steel by inhibiting the development of micro-cracks. Yet as regards steel, non-metallic inclusions have mostly a negative effect which is dependent on their content, size, shape and distribution. The mechanical properties and fatigue strength of structural materials should also be evaluated in view of contents of oxygen [1-3]. The presence of oxygen and non-metallic inclusions in steel is a natural consequence of physical and chemical processes during production. The shape of non-metallic inclusions may vary. Spheroidal inclusions are characteristic of steel which contains high levels of oxygen. The addition of small amounts of aluminum leads to partial deoxydation of steel and the formation of inclusions along the boundaries of austenite grains. Excessive amounts of powerful deoxidants contribute to the formation of large faceted inclusions [4]. Alloys subjected to variable loads require high-grade steels. Their properties are determined during complex tests that are costly and time consuming. For this reason, analyses that support quick determination of the evaluated properties are often used in industrial practice [5-6]. Fatigue strength is one of the evaluated properties of steel. Various functions, nomograms and coefficients are given in the literature for estimating fatigue strength as a function of tensile strength [7] in equation (1). They include other sensitivity coefficients such as the coefficient of material's sensitivity to cycle asymmetry, load type, etc.

$z_{g}=c R_{m}$

Coefficient $c$ is the quotient of fatigue strength $z_{g}$ divided by tensile strength $R_{m}$ at static load. To estimate tensile strength based on the results of non-destructive tests, coefficient $p$ was introduced in equation (2) to determine tensile strength as a function of hardness. 
$R_{m}=p H V$

Coefficients $c$ and $p$ were substituted with coefficient $k$, then:

$k=\frac{z_{g}}{H V}$

Equation (1) does not account for steel purity. For this reason, coefficient $c$ can take on a broad range of values. For steel samples subjected to rotary bending, it ranges from 0.36 to 0.6 of tensile strength $R_{m}$ [8].

The influence of impurities on fatigue strength has been researched extensively, but very few studies analyse the effect of impurities on the coefficient given by equation (3) which is used to estimate fatigue strength based on hardness, i.e. in non-destructive tests. Coefficient $\mathrm{k}$ is the quotient of fatigue strength $z_{g}$ divided by Vickers hardness HV. In this study, attempts were made to analyse the contents of oxygen on fatigue resistance coefficient $\mathrm{k}$ determined under rotary bending fatigue strength $z_{g o}$ of high purity steels produced in an industrial plant in electric furnace for various tempering options.

\section{METHODS}

The steel was melted in a 140-ton basic arc furnace. The study was performed on 6 heats produced in an industrial plant. The metal was tapped into a ladle, it was desulfurized and 7-ton ingots were uphill teemed. After tapping into a ladle, steel was additionally refined with argon. Gas was introduced through a porous brick, and the procedure was completed in 8-10 minutes. Billets with a square section of $100 \times 100 \mathrm{~mm}$ were rolled with the use of conventional methods. Billet samples were collected to determine: chemical composition - the content of alloy constituents was estimated with the use of LECO quantometer and conventional analytical methods, relative volume of non-metallic inclusions with the use of the extraction method.

It in aim of qualification of fatigue proprieties from every melting was taken 51 sections. The possession sections of the cylinders shapes are of about diameter $10 \mathrm{~mm}$. Their main axes are directed to direction of plastic processing simultaneously. It thermal processing was subjected was in aim of differentiation of building of structural sample. It depended on hardening from austenitizing by 30 minutes in temperature $880^{\circ} \mathrm{C}$ after which it had followed quenching in water, for what was applied drawing. Tempering depended on warming by 120 minutes material in temperature $200,300,400,500$ or $600{ }^{\circ} \mathrm{C}$ and cooling down on air. Heat treatments were selected to produce heats with different microstructure of steel, from hard microstructure of tempered martensite, through sorbitol to the ductile microstructure obtained by spheroidization.

Examination was realized on calling out to rotatory curving machine about frequency of pendulum cycles: 6000 periods on minute. For basis was accepted was on fatigue defining endurance level $10^{7}$ cycles. During the test, the applied load was gradually reduced in steps of $40 \mathrm{MPa}$ (to support the determinations within the endurance limit). Load values were selected to produce $10^{4}-10^{6}$ cycles characterizing endurance limits [1].

The general form of the mathematical model is presented by equation (4):

$\mathrm{k}_{\text {(temp. tempered) }}=\mathrm{a} O+b$

where:

$k$ - fatigue resistance coefficient,

$O$ - arithmetic average contents of oxygen in steel, \%,

$a, b$ - coefficients of the equation.

The significance of correlation coefficients $r$ was determined on the basis of the critical value of the Student's $t$-distribution for a significance level $\alpha=0.05$ and the number of degrees of freedom $f=n-1$.

\section{RESULTS}

The average chemical composition of the analysed steel is presented in Table 1. 
Table 1 Average chemical composition of the analysed steel (wt\%).

\begin{tabular}{|c|c|c|c|c|c|c|c|c|c|c|}
\hline $\mathrm{C}$ & $\mathrm{Mn}$ & $\mathrm{Si}$ & $\mathrm{P}$ & $\mathrm{S}$ & $\mathrm{Cr}$ & $\mathrm{Ni}$ & $\mathrm{Mo}$ & $\mathrm{Cu}$ & $\mathrm{B}$ & $\mathrm{O}$ \\
\hline 0.23 & 1.20 & 0.27 & 0.021 & 0.011 & 0.46 & 0.46 & 0.22 & 0.14 & 0.003 & 0.05 \\
\hline
\end{tabular}

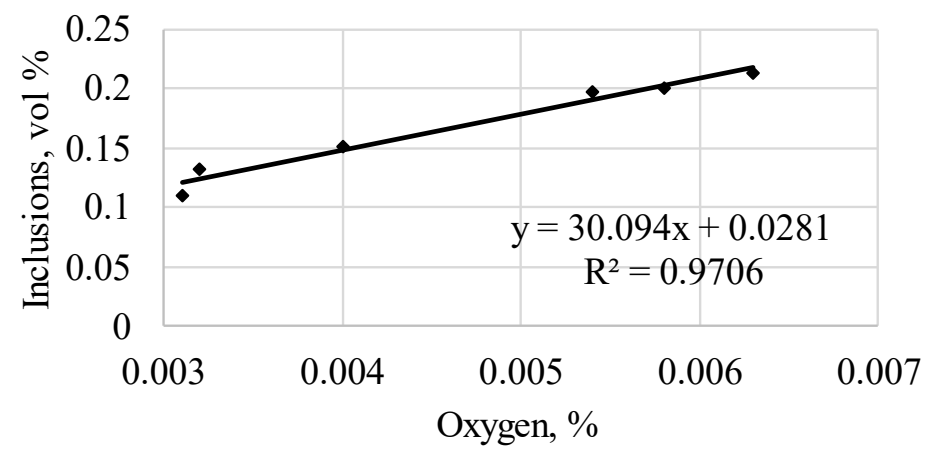

Figure 1 Arithmetic average volume of impurities subject to contents of oxygen

The arithmetic average inclusions $\mathrm{V}$ to contents of oxygen $\mathrm{O}$ of steel is presented in Figure 1, regression equation and correlation coefficient $r$ at (5):

$V=30.094 \cdot O+0.0281$ and $r=0.9852$

Fatigue resistance coefficient $k$ determined for bending fatigue strength of steel hardened and tempered at $200^{\circ} \mathrm{C}$ in dependence on arithmetic average oxygen are presented in Figure 2, regression equation and correlation coefficient $r$ at equation (6):

$\mathrm{k}_{200}=108.85 \cdot \mathrm{O}+0.5423$ and $\mathrm{r}=0.9471$

Fatigue resistance coefficient $\mathrm{k}$ determined for bending fatigue strength of steel hardened and tempered at $300{ }^{\circ} \mathrm{C}$ in dependence on arithmetic average oxygen are presented in Figure 3, regression equation and correlation coefficient $r$ at equation (7):

$\mathrm{k}_{300}=51.748 \cdot 0+0.7336$ and $\mathrm{r}=0.8950$

Fatigue resistance coefficient $\mathrm{k}$ determined for bending fatigue strength of steel hardened and tempered at $400{ }^{\circ} \mathrm{C}$ in dependence on arithmetic average oxygen are presented in Figure 4, regression equation and correlation coefficient $r$ at equation (8):

$\mathrm{k}_{400}=92.063 \cdot \mathrm{O}+0.5651$ and $\mathrm{r}=0.8862$

Fatigue resistance coefficient $\mathrm{k}$ determined for bending fatigue strength of steel hardened and tempered at $500{ }^{\circ} \mathrm{C}$ in dependence on arithmetic average oxygen are presented in Figure 5, regression equation and correlation coefficient $r$ at equation (9);

$\mathrm{k}_{500}=72.028 \cdot \mathrm{O}+0.5829$ and $\mathrm{r}=0.9454$

Fatigue resistance coefficient $\mathrm{k}$ determined for bending fatigue strength of steel hardened and tempered at $600{ }^{\circ} \mathrm{C}$ in dependence on arithmetic average oxygen are presented in Figure 6, regression equation and correlation coefficient $r$ at equation (10): 


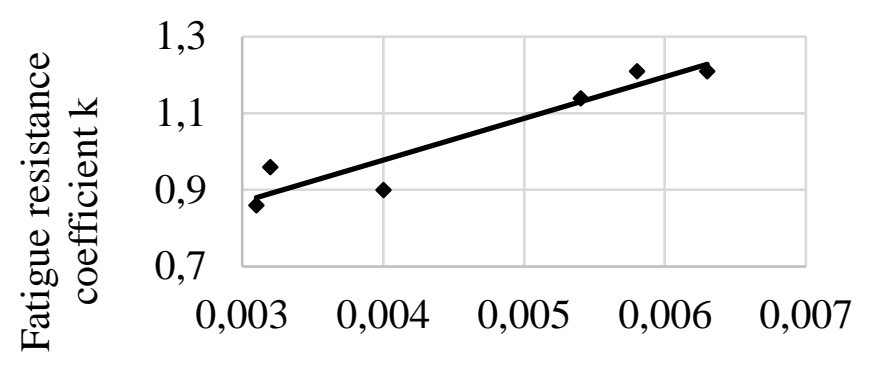

Oxygen, $\%$

Figure 2 Fatigue resistance coefficient $\mathrm{k}$ of steel hardened and tempered at $200{ }^{\circ} \mathrm{C}$ subject to oxygen

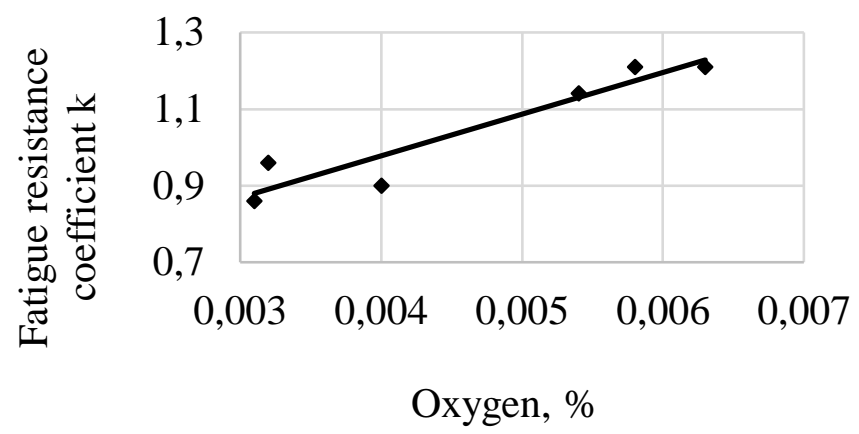

Figure 3 Fatigue resistance coefficient $\mathrm{k}$ of steel hardened and tempered at $300{ }^{\circ} \mathrm{C}$ subject to oxygen

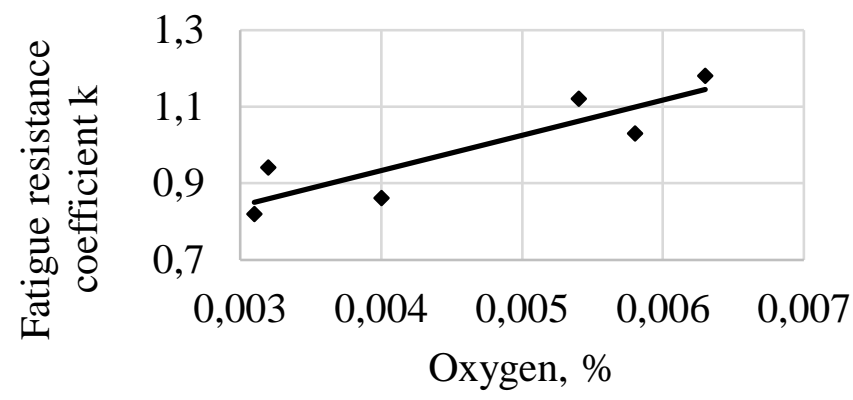

Figure 4 Fatigue resistance coefficient $\mathrm{k}$ of steel hardened and tempered at $400{ }^{\circ} \mathrm{C}$ subject to oxygen

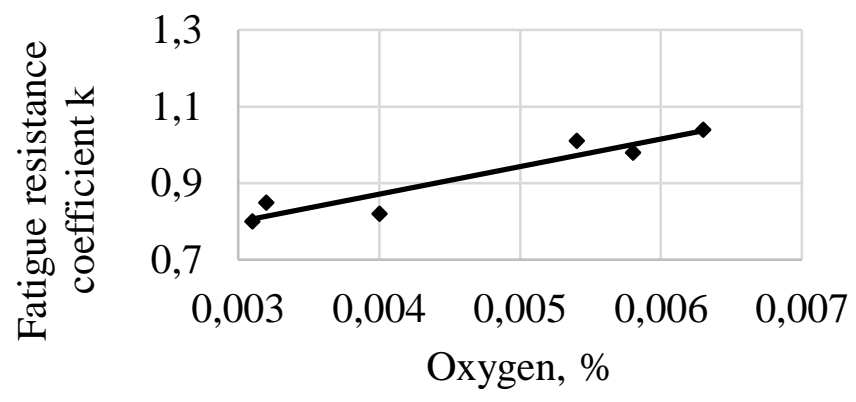

Figure 5 Fatigue resistance coefficient $\mathrm{k}$ of steel hardened and tempered at $500{ }^{\circ} \mathrm{C}$ subject to oxygen 


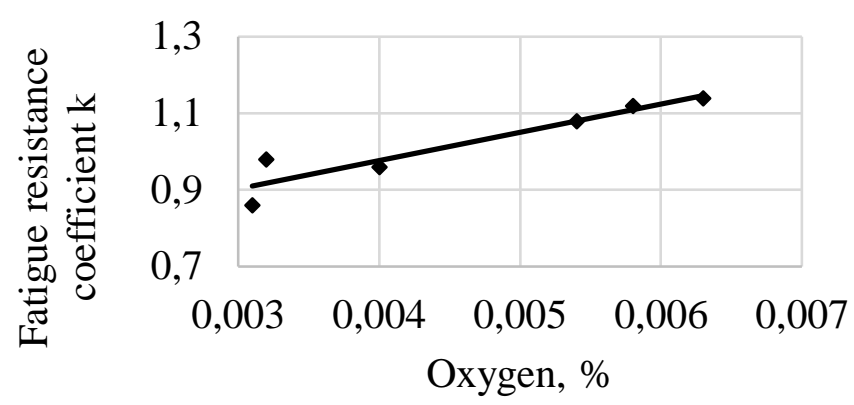

Figure 6 Fatigue resistance coefficient $\mathrm{k}$ of steel hardened and tempered at $600{ }^{\circ} \mathrm{C}$ subject to oxygen

Fatigue resistance coefficient $\mathrm{k}$ determined for bending fatigue strength of steel hardened and tempered at $200,300,400,500$ and $600{ }^{\circ} \mathrm{C}$ in dependence on arithmetic average oxygen are presented in Figure 7, regression equation and correlation coefficient $r$ at equation (11):

$\mathrm{k}_{200-600}=79.692 \cdot \mathrm{O}+0.6211$ and $\mathrm{r}=0.8349$

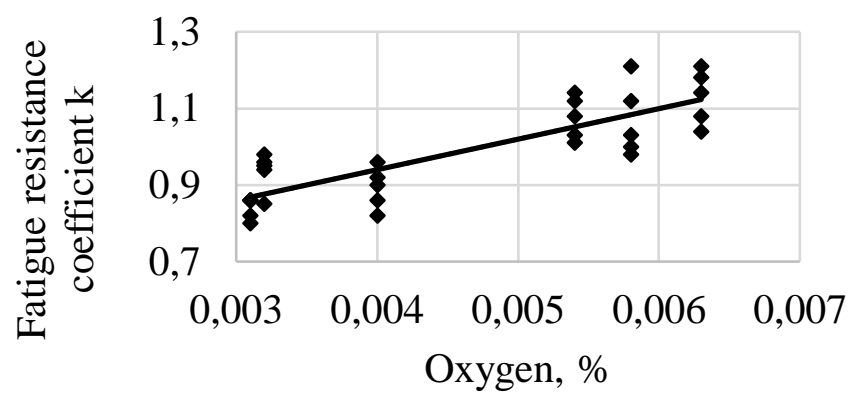

Figure 7 Fatigue resistance coefficient $\mathrm{k}$ of steel hardened and tempered at 200, 300, 400, 500 and $600{ }^{\circ} \mathrm{C}$ subject to oxygen

\section{CONCLUSIONS}

The results of the study indicate that:

- $\quad$ relative volume of non-metallic inclusions in research steels, statistically significant correlations was verified by Student's t-test, is correlated with the oxygen;

- $\quad$ results of the study indicate that fatigue resistance coefficient $\mathrm{k}$, represented by fatigue strength during rotary bending, is correlated with the contents of oxygen. The presence of statistically significant correlations was verified by Student's t-test;

- $\quad$ Arithmetic average volume of impurities $V$ increased with the increased of oxygen contents (Figure 1), which is a natural process. At the same time, a high correlation coefficient $(r>0.98)$ confirms that the equation is statistically significant and that the tests were conducted correctly;

- $\quad$ the Fatigue resistance coefficient $k$ increased with the volume of oxygen increased (Figures 2-7). At the same time, a high correlation coefficient $(r>0.88)$ confirms that the equationa are statistically significant;

- the above suggests that an increase in the number of inclusions in plastic structural steel increases the value of $\mathrm{zg} / \mathrm{HV}$;

- $\quad$ the smallest effect of oxygen content on the coefficient $\mathrm{k}$ was found for steel after medium tempering $(3000 \mathrm{C})$; 
- $\quad$ an analysis of regression coefficients and fatigue resistance coefficients $k$ indicates that changes in coefficients $k$ as a function of oxygen contents can be described with statistical satisfactory accuracy by a single equation (11) at all tempering temperatures $(r>0.8)$.

The study of the influence of oxygen on fatigue resistance is very important both for similar fatigue tests [9] and for the machine industry (including railways [10-12]), power engineering [13] and construction [14]. The results may also be valuable for other material [15] and welding [16] tests, especially in the case of devices and machines operating in corrosively aggressive environments $[17,18]$.

\section{REFERENCES}

[1] KOCAŃDA, S.. Zmęczeniowe pękanie metali. Warszawa: WNT, 1985.

[2] SPRIESTERSBACH, D., GRAD, P., KERSCHER, E. Influence of different non-metallic inclusion types on the crack initiation in high-strength steels in the VHCF regime. Int. J. Fatigue. 2014, vol. 64, pp. 114-120.

[3] BERETTA, S., MURAKAMI, Y. Largest-Extreme-Value Distribution Analysis of Multiple Inclusion Types in Determining Steel Cleanliness. Metallurgical and Materials Transactions. 2001, vol. 32B, pp. 517-523.

[4] MURAKAMI, Y. Metal fatigue: Effects of small defects and inclusions. Amsterdam: Elsevier, 2002.

[5] ČAPKA, A., RNSNAKOVA, S., ŽALUDEK, M., KARVANIS, K.. Fatigue Life of Al-Honeycomb Core Composites Construction. Manufa. Technol. 2018, vol. 18, pp. 727-731.

[6] BELAN, J., VAŠKO, A., KUCHARIKOVÁ, L., LILIOVÁ, E., MATVIJA, M. The High-Temperature Loading Influence on Orthorhombic NbNb DOa $\delta$-Phase Formation and its Effect on Fatigue Lifetime in Alloy 718. Manufa. Technol. 2018, vol. 18, pp. 875-882.

[7] KOCAŃDA, S., SZALA, J. Podstawy obliczeń zmęczeniowych. Warszawa: PWN, 1985.

[8] Poradnik inżyniera mechanika. Warszawa: WNT, 1970.

[9] ULEWICZ, R., NOVÝ, F., SELEJDAK, J. Fatigue strength of ductile iron in ultra-high cycle regime. Adv. Mater. Res.-Switz. 2014, vol. 874, pp. 43-48.

[10] KRYNKE, M., BORKOWSKI, S., SELEJDAK, J. Analysis of influence of bearing clearance on the static carrying capacity of multi-row slewing bearings. Periodica Polytechnica Transport. Eng. 2014, vol. 42, pp. 43-48.

[11] KRYNKE, M., ULEWICZ, R. Analysis of the influence of slewing bearing mounting on their static load capacity. Transportation Research Procedia. 2019, vol. 40, pp. 745-750.

[12] MYSŁEK, A. Crack propagation analysis in selected railway bogie components. Technical Transactions. 2020, vol.117, no. e2020017.

[13] RADEK, N., ORMAN, Ł.J., PIETRASZEK, J., BRONČEK, J. Verification of correlations for pool boiling heat transfer on horizontal meshed heaters. Materials Research Proceedings. 2020, vol. 17, pp. 185-190.

[14] MAJEWSKI, G., ORMAN, Ł.J., TELEJKO, M., RADEK, N., PIETRASZEK, J., DUDEK, A. Assessment of thermal comfort in the intelligent buildings in view of providing high quality indoor environment. Energies. 2020, vol. 13, no. 1973.

[15] SZCZOTOK, A., PIETRASZEK, J., RADEK, N. Metallographic Study and Repeatability Analysis of Y' Phase Precipitates in Cored, Thin-Walled Castings Made from IN713C Superalloy. Arch. Metall. Mater. 2017, vol. 62, pp. 595-601.

[16] PATEK, M., KONAR, R., SLADEK, A., RADEK, N. Non-destructive testing of split sleeve welds by the ultrasonic TOFD method. Manuf. Technol. 2014, vol. 14, pp. 403-407.

[17] LIPINSKI, T. Corrosion effect of $20 \% \mathrm{NaCl}$ solution on basic carbon structural S235JR steel. Engineering for Rural Development. 2017, vol. 16, pp. 1069-1074.

[18] SKRZYPCZAK-PIETRASZEK, E., URBANSKA, A., ZMUDZKI, P., PIETRASZEK, J. Elicitation with methyl jasmonate combined with cultivation in the Plantform ${ }^{\mathrm{TM}}$ temporary immersion bioreactor highly increases the accumulation of selected centellosides and phenolics in Centella asiatica (L.) Urban shoot culture. Engineering in Life Sciences. 2019. vol. 19, pp.931-943. 